\title{
POBREZA EN HOGARES CON JEFATURA FEMENINA EN ARGENTINA. UNA COMPARACIÓN ENTRE EL NORTE GRANDE Y EL RESTO DEL PAÍS
}

\section{POVERTY IN FEMALE-HEADED HOUSEHOLDS. COMPARISON BETWEEN NORTH REGION OF ARGENTINA AND TOTAL COUNTRY}

\author{
Jorge Paz \\ CONICET- Instituto de Estudios Laborales y del \\ Desarrollo Económico \\ Universidad Nacional de Salta \\ Salta, Salta, Argentina \\ pazjor@gmail.com
}

\author{
Carla Arévalo \\ CONICET- Instituto de Estudios Laborales y del \\ Desarrollo Económico \\ Universidad Nacional de Salta \\ Salta, Salta, Argentina \\ carla.arevalo.wierna@gmail.com
}

Fecha de recepción: 29/09/2020 - Fecha de revisión: 22/10/2020 - Fecha de aprobación: 24/11/2020 DOI: https://doi.org/10.36995/j.visiondefuturo.2021.25.02.001.es

\section{RESUMEN}

La pobreza en hogares con jefatura femenina ha sido objeto de numerosos estudios en varios países del mundo, pero no en la Argentina. En este trabajo abordamos ese tema y exploramos la situación del Norte Grande de Argentina (NGA). Esta región tiene los niveles de pobreza más elevados del país, tanto a juzgar por la dimensión monetaria como no monetaria (González, 2019), y niveles comparativamente altos también de personas viviendo en hogares monoparentales y extensos, en los que los riesgos de pobreza son mayores que en el resto de hogares. La pregunta que intentamos responder son dos: a) si existe evidencia de feminización de pobreza en el país, y b) si el NGA registra un nivel de feminización de pobreza mayor que la media nacional, luego de controlados los factores que determinan la pobreza de los hogares. Encontramos que la Argentina experimenta el fenómeno de feminización de pobreza, que la feminización de la pobreza aumentó en los últimos siete años (desde 2013) y que la región del NGA no presenta niveles de feminización de pobreza mayores al resto del país una vez controlados los factores determinantes de la pobreza.

PALABRAS CLAVE: Pobreza femenina; Feminización de la pobreza; Argentina.

\section{ABSTRACT}

Poverty in female-headed households has been the subject of several studies in various countries of the world, but not in Argentina. In this paper we address this issue and explore the situation in the Norte Grande in Argentina (NGA). This region has the highest poverty levels in the country, considering both the monetary and non-monetary dimensions (González, 2019), and comparatively high levels also of people living in single-parent and large households, in

\footnotetext{
“Visión de Futuro" Año 18, Volumen N²5 N², Edición Especial-III Congreso Regional de Economía del Norte Grande-Pág 1-30 URL de la Revista: http://visiondefuturo.fce.unam.edu.ar/index.php/visiondefuturo/index URL del Documento: https://visiondefuturo.fce.unam.edu.ar/index.php/visiondefuturo/issue/view/20 ISSN 1668 - 8708 - Versión en Línea 
which the risks of poverty are greater than in other households. The questions we are trying to answer are two: a) if there is evidence of feminization of poverty in the country, and b) if the NGA registers a level of feminization of poverty higher than the national average, after controlling factors that determine poverty of homes. We find that Argentina experiences the phenomenon of feminization of poverty, that the feminization of poverty has increased in the last seven years (since 2013) and that the NGA region does not present levels of feminization of poverty greater than the rest of the country once controlled the determinants of poverty.

KEY WORDS: Poverty; Female poverty; Argentina.

\section{INTRODUCCIÓN}

La feminización de la pobreza como tema de investigación es interesante por dos motivos: porque aborda uno de los principales problemas del bienestar (sino el principal), la pobreza, y lo conecta con la desigualdad por género. Excepto en algunos países, principalmente asiáticos (Kynch \& Sen, 1983), no hay diferencias de pobreza entre hombres y mujeres en la población en general: la proporción de hombres y mujeres en la pobreza es la misma que la proporción de hombres y mujeres en la población total. ${ }^{1}$ Es claro que esto depende crucialmente de la manera de medir pobreza que se adopta. Al usar el hogar como unidad de análisis es lógico esperar un resultado de este tipo. Entonces, el problema de la feminización de la pobreza aparece cuando se evalúa las privaciones según el sexo de la persona que encabeza el hogar: el/la jefa/e o persona de referencia (PR) del hogar. La feminización de la pobreza se verifica entonces si la pobreza, medida de alguna manera, es mayor en los hogares con jefatura femenina (HJF) que en los hogares con jefatura masculina (HJM). Podría decirse además que la misma palabra "feminización" feminización, tiene una connotación dinámica, por lo que se podría pedir a este concepto no sólo una disparidad de pobreza desfavorable a las mujeres, sino también que esa disparidad esté en aumento con el paso del tiempo.

Hay varios motivos que pueden dar lugar a esta mayor probabilidad de pobreza de los HJF. Las mujeres participan menos que los hombres en el mercado laboral y las que participan obtienen resultados menos satisfactorios en términos de empleo (el desempleo femenino es mayor que el masculino) y de remuneraciones. En la Argentina, la tasa de actividad de las mujeres es de un $49 \%$ frente a un $69 \%$ de la de varones, y la tasa de desempleo femenina es del $11 \%$ versus el $9 \%$ de la masculina (INDEC, 2020a). Además, los estudios dan cuenta de

\footnotetext{
${ }^{1}$ En Argentina, en el año 2020, el 48\% de la población urbana relevada por la Encuesta Permanente de hogares son hombres y el 52\% mujeres. Entre los pobres esa relación es $49 \%$ y $51 \%$, respectivamente.

"Visión de Futuro" Año 18, Volumen N$^{\circ} 25$ Nº 2, Edición Especial-III Congreso Regional de Economía del Norte Grande-Pág 1-30 URL de la Revista: http://visiondefuturo.fce.unam.edu.ar/index.php/visiondefuturo/index

URL del Documento: https://visiondefuturo.fce.unam.edu.ar/index.php/visiondefuturo/issue/view/20

ISSN 1668 - 8708 - Versión en Línea

E-mail: revistacientifica@fce.unam.edu.ar
} 
una brecha de remuneraciones cercana al 30\% favorable a los hombres (MTESS, 2019) y muestran que luego de controlar por diversos determinantes, queda una parte que sería atribuible a la discriminación (Paz, 2019). En suma, la condición de actividad de las mujeres, el hecho de estar estadísticamente inactiva, ocupada o desocupada, la ubica en una situación de desventaja respecto de sus pares masculinos. Por otro lado, una buena parte de estas mujeres están a cargo de sus hijos, son madres solteras, separadas o viudas, que enfrentan un hogar con un mayor número de niñas y niños, y, en algunos casos con personas mayores. Esto acrecienta la vulnerabilidad que proviene del mercado de trabajo poniendo también en riesgo a la niñez y constituyéndose en un factor importante para explicar la transmisión intergeneracional de la pobreza.

En la Argentina la diversidad regional de los niveles de bienestar es muy marcada. Las regiones del Nordeste y del Noroeste (NEA y NOA) tienen los niveles más elevados de pobreza del país, y concurren en estas regiones también factores que favorecen la persistencia de estos niveles de pobreza: un nivel educativo comparativamente menor que otras regiones de país (como el Centro y la Patagonia, por ejemplo), mercados de trabajo con menor dinamismo, y un número mayor de familias monoparentales y extensas que, como se dijo al principio, registran niveles de pobreza superiores al promedio. Esta es una situación estructural y los peores resultados en términos de bienestar se reflejan también en mayor pobreza desde una perspectiva multidimensional. Un estudio publicado recientemente muestra que, de los diez distritos más multidimensionalmente más pobres del país, ocho corresponden al Norte Grande de Argentina (NGA), región mayor que incluye las regiones menores del NEA y NOA (González, 2019).

El objetivo del presente artículo es, por un lado, recopilar evidencia y evaluar con ella la posible existencia de feminización de la pobreza en el país. Luego de hecho esto, se pretende comparar la pobreza en hogares con jefatura femenina de la región del NGA con la del resto del país y determinar en qué medida los factores correlacionados con la pobreza por ingreso operan de manera diferencial en esta región, o si los diferenciales interregionales se explican por los factores que hacen más vulnerables a los hogares y que se encuentran en proporción mayor en la gran región del NGA. De los resultados se pretende concluir un hecho generalizable: si en los ámbitos geográficos que presentan niveles de pobreza más elevados, tienen, a la vez, un nivel más elevado de feminización de pobreza.

El documento se ha organizado de la siguiente manera. En la próxima sección se plantea el marco conceptual que justifica la elección de las variables que se usan para explicar la pobreza monetaria en general. Se formulan también allí las hipótesis de trabajo que guían el desarrollo de las secciones siguientes. Se repasa luego la literatura relacionada con el tema abordado poniendo el énfasis en la mayor prevalencia de la pobreza en hogares con jefatura 
femenina más que en las diferencias interregionales. La sección IV hace un repaso sobre el nivel y la evolución de la feminización de la pobreza en la Argentina. La sección $\mathrm{V}$ presenta los datos usados y la estrategia metodológica seguida para poner a prueba las hipótesis de trabajo. La sección VI presenta y discute los resultados principales. El documento contiene también unas conclusiones y una agenda para trabajo futuro. Hacia el final se incorporó un apéndice de tablas que apoyan los hallazgos discutidos en el cuerpo central del texto, principalmente en la sección VI.

\section{DESARROLLO}

\section{Marco conceptual e hipótesis de trabajo}

Dado que la pobreza monetaria (en adelante pobreza) suele computarse usando al hogar como unidad de análisis, hay dos factores que se relacionan en una tasa de pobreza: los ingresos (o el consumo) y la necesidad de gasto del hogar. Del balance entre ambos emerge la identificación: si los primeros son estrictamente menores que los gastos necesarios para cubrir una ingesta energética y calórica mínima indispensable para la supervivencia, se dice que el hogar es pobre y, con ello, todos sus integrantes. De esta manera, los factores que determinan el nivel de los ingresos o consumo y los factores que determinan los gastos, son los denominados determinantes profundos de la pobreza, mientras que el ingreso y la necesidad de consumo son los determinantes próximos. Los ingresos dependen del número de perceptoras/es por hogar, de las remuneraciones (por unidad de dotación) de cada una/o de ellas/os y de las dotaciones con que cuentan (educación, capital social y familiar, lugar en el que residen, entre otros). Los gastos, por su parte, dependen del tamaño y de la composición por edad y sexo del hogar, esto es de las unidades de adulto equivalente de cada hogar. $^{2}$

La pregunta interesa aquí tiene que ver con las posibles razones que generan una pobreza mayor en aquellos hogares regidos por mujeres. Se puede ligar el esquema planteado en el primer párrafo y ensayar una respuesta. Es un hecho muy estudiado que las mujeres tienen menos acceso a activos que generan ingresos, como la tierra, el crédito, el capital físico y humano y la tecnología. ${ }^{3}$ Al mismo tiempo, las mujeres generalmente enfrentan mayores limitaciones de tiempo, ya que tienen que cumplir múltiples roles dentro del hogar, tanto en las actividades de producción doméstica como en los roles domésticos como el cuidado de niñas, niños y personas mayores, además de los quehaceres domésticos y tareas

\footnotetext{
2 El concepto de adulto equivalente es masculino, dado que se trata, al menos en la Argentina, de un hombre entre 30 y 59 años que realiza una actividad moderada.

${ }^{3}$ Quizá el tema del capital humano en Argentina no es tan palpable, pero sí en otros países del mundo.

"Visión de Futuro" Año 18, Volumen No 25 № 2, Edición Especial-III Congreso Regional de Economía del Norte Grande-Pág 1-30 URL de la Revista: http://visiondefuturo.fce.unam.edu.ar/index.php/visiondefuturo/index

URL del Documento: https://visiondefuturo.fce.unam.edu.ar/index.php/visiondefuturo/issue/view/20

ISSN 1668 - 8708 - Versión en Línea

E-mail: revistacientifica@fce.unam.edu.ar
} 
que demandan la atención del hogar. La demanda por tiempo para realizar tareas del hogar compite con la demanda por tiempo para trabajo remunerado, con lo cual, si es que las mujeres se especializan en la realización de las tareas domésticas no remuneradas, van a disponer menos tiempo que los hombres para dedicarlo a obtener ingresos.

Con estos elementos es posible plantar como hipótesis que los HJF tienen una probabilidad mayor de encontrarse en la pobreza tanto por el lado de los ingresos como por el de los gastos del hogar. Los ingresos de las mujeres, que reflejan desventajas de inserción en el mercado laboral, son inferiores a los que obtienen los hombres por el mismo trabajo. Los motivos centrales de por qué esto es así tiene que ver con el menor número de horas dedicadas al trabajo remunerado, debido a las obligaciones domésticas y de cuidado de personas y todos los temas asociados a los empleos que permiten combinar amos tipos de tareas: mayor informalidad, menores posibilidades de progreso e intermitencias en la participación, debidas fundamentalmente a las experiencias reproductivas. Los estudios encuentran también que controlados estos factores persiste una proporción de la brecha de ingresos que no se explica por ninguna de estas variables.

Los gastos de los HJF pueden ser mayores por varios motivos. En primer lugar, es probable que sean las mujeres, y no los hombres, los que asuman responsabilidades de cuidado de niñas y niños ante la disolución de la pareja. Ocurre otro tanto a madres solteras que son las responsables de la crianza de sus hijos. Entre las mujeres de edades avanzadas y debido al diferencial de esperanza de vida de éstas en comparación con el de los hombres, la viudez puede convertirse en un factor de privación, quizá no tan importante en Argentina a partir de la implementación de la moratoria previsional. También es probable que, ante ausencia de mecanismos formales de protección para las personas mayores, las mujeres (hijas) se hagan cargo del cuidado de sus progenitores cuando éstos no puedan valerse por sus propios medios por problemas de salud o asociados. Esto es tanto más probable cuanto mejor ubicadas económicamente estén las mujeres jefas de hogar. Esto último podría resultar paradójico: experimentar pobreza por aumento en el número de personas en el hogar, por tener ingresos suficientes para cubrir la canasta básica de bienes.

En suma, es probable que muchas mujeres no dispongan de ingresos propios para hacer frente a las necesidades del hogar. Además, entre aquellas que perciben ingresos es probable que éstos no sean suficientes para afrontar los gastos que demanda el funcionamiento del hogar. Como se dijo antes, esto puede deberse a que las mujeres reciben remuneraciones más bajas y/o a que su inserción laboral es más precaria y segregada que la de los hombres (Paz, 2020). También está claro que una proporción no menor de estas mujeres cuenta con escasa experiencia laboral por dedicarse principalmente a las tareas del hogar, generando una participación intermitente en el mercado de trabajo. La pobreza en

\footnotetext{
“Visión de Futuro" Año 18, Volumen No 25 N² 2, Edición Especial-III Congreso Regional de Economía del Norte Grande-Pág 1-30 URL de la Revista: http://visiondefuturo.fce.unam.edu.ar/index.php/visiondefuturo/index

URL del Documento: https://visiondefuturo.fce.unam.edu.ar/index.php/visiondefuturo/issue/view/20

ISSN 1668 - 8708 - Versión en Línea

E-mail: revistacientifica@fce.unam.edu.ar
} 
hogares con jefatura femenina puede provenir también de necesidad de estas mujeres de compatibilizar trabajo doméstico y remunerado, de la responsabilidad sobre la crianza y cuidado de niños y de su relativo aislamiento, falta/ausencia de vínculos sociales. Estos factores convergen a generar una menor calidad de vida para ella y su familia y mayor pobreza.

\section{Literatura pertinente}

Precisar qué se entiende por feminización de la pobreza es un detalle crucial en este tipo de estudios. Como puede apreciarse en la literatura sobre el tema, hay varias maneras de definir el fenómeno y esto resulta crucial para la exploración empírica y el descubrimiento de patrones. Como lo plantean Bradshaw et al. (2018) las diferencias metodológicas en qué, cómo y quién es el foco de la medición, pueden influir en los patrones de feminización de la pobreza. Y estas mismas autoras distinguen entre la feminización de la jefatura de hogar, la feminización de la pobreza y la feminización de los programas de lucha contra la pobreza, considerándolos desafíos fundamentales para corregir las brechas de género en la pobreza dentro de la Agenda 2030 para el Desarrollo Sostenible. En el mismo sentido Medeiros \& Costa (2008) sostienen que la mayoría de los significados de la feminización de la pobreza, son relevantes para la política pública y la promoción de la igualdad de género, y agregan que, por ese motivo, en lugar de intentar argumentar a favor de una única definición, la investigación en esta área debería intentar abarcar tantas definiciones como sea posible y relevante.

¿Qué es lo que se entiende entonces por feminización de la pobreza? Aguilar (2011) sitúa el origen del concepto en el trabajo Diana Pearce (Pearce, 1978), centrado particularmente en la descripción empírica de una tendencia inquietante: el aumento de la pobreza por ingresos en hogares encabezados por mujeres en los EEUU. Pearce (1978) observó que la tasa de prevalencia de la pobreza en esos hogares había pasado del $10 \%$ en 1950 al 14\% en 1976, revelando una tendencia al deterioro de las condiciones de vida en este tipo de hogares. La feminización de la pobreza es definida en sus orígenes como un aumento de la pobreza en hogares encabezados por mujeres. Nótese que no solamente se está diferenciando a los hogares por el sexo de la PR, sino que se está analizando el comportamiento temporal de la diferencia de niveles de pobreza en hogares encabezados por mujeres (HJF) y hogares encabezados por hombres (HJM).

Partiendo de esta idea fundante, Snyder et al. (2006) encuentran que la pobreza es más alta en los hogares encabezados por mujeres con hijos, y que, además, no tienen otras/os perceptores de ingresos en los hogares en los que ellas residen. $\mathrm{O}$, lo que es lo mismo decir,

\footnotetext{
“Visión de Futuro" Año 18, Volumen N²5 N², Edición Especial-III Congreso Regional de Economía del Norte Grande-Pág 1-30 URL de la Revista: http://visiondefuturo.fce.unam.edu.ar/index.php/visiondefuturo/index

URL del Documento: https://visiondefuturo.fce.unam.edu.ar/index.php/visiondefuturo/issue/view/20 
los ingresos obtenidos por otros miembros del hogar mantienen fuera de la pobreza a muchos hogares encabezados por mujeres que viven en pareja, como así también a hogares encabezados por mujeres mayores. Estos autores muestran también que los ingresos provenientes de la jubilación y del Seguro Social juegan un rol importante para que los hogares encabezados por abuelas puedan permanecer fuera de la pobreza. Podría extenderse esta idea a los hogares encabezados por mujeres con hijas/os en edad de trabajar. Es probable que el aporte de estos componentes del hogar permita al hogar estar en una situación de no pobreza, y que los hogares que no cuentan con esos aportes sean pobres.

Regresando a la idea de dinámica temporal, AlAzzawi (2015) se pregunta si ha habido una feminización de la pobreza en Egipto durante los últimos 15 años, ubicando, su período de interés en el cual la pobreza aumentó y se han producido importantes cambios económicos, sociales y políticos. Los resultados sugieren que la pobreza es más prevalente entre los hogares encabezados por mujeres en comparación con los hogares encabezados por hombres, pero que los hogares de parejas casadas son de hecho más pobres que ambos durante la mayor parte de los años bajo estudio. La brecha rural-urbana también es un factor muy importante que determina la pobreza.

Se cuenta con menos literatura internacional relacionada con los factores determinantes. El análisis de la desventaja femenina en el mercado de trabajo como determinante de la pobreza es abordado por Aisa (2019) usando datos de ingresos laborales para varios países de Europa. La autora encuentra una paridad en los resultados de hombres y mujeres pero que afirma que es sólo aparente, dado que las mujeres tienen dotaciones educativas y de otro tipo (ocupadas en puestos profesionales, por ejemplo) que las sitúa en una posición más favorable que los hombres en tanto potencialidad de ingresos. Su hipótesis apunta a los trabajos a tiempo parcial que son mayoritariamente ocupados por las mujeres (y más aún por las mujeres más educadas) y que podría tener que ver con la necesidad de conciliar el trabajo doméstico remunerado con el no remunerado.

Para América Latina los estudios son más escasos. Además de advertir cuestiones cruciales como que los hogares pobres encabezados por mujeres experimentan una triple desventaja (la pobreza, la discriminación de género y la ausencia de apoyo), el trabajo de Buvinic \& Gupta (1997) es uno de los primeros en presentar evidencia compacta sobre este tema para países en desarrollo en general y de la región en particular. Estos autores examinaron 61 que abordaban la relación entre la jefatura femenina y la pobreza. 36/61 estudios encontrados, utilizando una variedad de indicadores de pobreza muestran que los hogares encabezados por mujeres están sobrerrepresentados entre los pobres. Otros quince estudios encontraron que la pobreza estaba asociada con ciertos tipos de mujeres jefas, o que la asociación aparecía para ciertos indicadores de pobreza y no para otros. Destacan, 
además, que sólo ocho de los 61 informes (13\%) no mostraron evidencia empírica para la hipótesis de la mayor pobreza de los hogares encabezados por mujeres.

Por su parte Liu et al. (2017) analizan el aumento de la proporción de hogares con jefatura femenina en varios países de América Latina usando datos censales. Relacionan esta tendencia con los cambios en los arreglos de vida y condiciones materiales de vida del hogar. Ellos encuentran que, en la mayoría de los 14 países analizados, es cada vez más probable que las mujeres sean jefas de hogar, independientemente del estrado civil y que es dicho estado, más que el sexo de la persona de referencia del hogar, es el que determina las condiciones de vida del hogar. Liu et al. (2017) destacan el matiz de las situaciones familiares y el empoderamiento femenino que conduce a la jefatura de hogar.

Si bien los estudios empíricos parecen confirmar la hipótesis de la feminización de la pobreza, los resultados no son concluyentes. Por ejemplo, Wright (1992) aplicando una medida de pobreza que permite descomponer la pobreza total en masculina y femenina, encuentra que no hay razones para sostener que exista feminización de la pobreza general en Gran Bretaña. El concepto usado por esta autora para este fenómeno es un aumento de la disparidad entre hombres y mujeres. Ella destaca que, si bien las mujeres están sobrerrepresentadas entre las/os pobres y que las tasas de pobreza estimadas son más altas para las mujeres en comparación con los hombres, la segunda desventaja basada en el género no ha aumentado entre 1968 y 1986. Esto la lleva a colegir de que no hay apoyo para la hipótesis de que ha habido una feminización de la pobreza en Gran Bretaña.

Sí proporciona evidencia de feminización de pobreza en hogares monoparentales. En este sentido destaca los hechos siguientes: a) la pobreza en hogares monoparentales y unipersonales es mayor que la de otro tipo de hogares; b) la proporción de hogares monoparentales y unipersonales en el total de hogares ha aumentado con el tiempo; c) la gran mayoría de los hogares monoparentales están encabezados por mujeres; y d) los unipersonales encabezados por mujeres, principalmente personas mayores, ha aumentado con el tiempo. Estos hechos podrían haber aumentado la representación de las mujeres en la pobreza total y haber provocado un proceso de feminización de pobreza en Gran Bretaña.

Medeiros \& Costa (2008) tampoco encuentran evidencias contundentes de un proceso de feminización de la pobreza en países de América Latina. Sostienen que, si bien existe una sobrerrepresentación de personas pobres en hogares encabezados por mujeres, no es correcto colegir feminización de pobreza y marcan la gran sensibilidad de los resultados a los cambios en los valores de la línea de pobreza. Estos autores advierten que, si bien encuentran que las personas que residen en hogares encabezados por mujeres están sobrerrepresentadas entre los pobres, no hay evidencia clara de una feminización reciente y generalizada de la pobreza en los países latinoamericanos examinados por ellos.

\footnotetext{
"Visión de Futuro" Año 18, Volumen No 25 N² 2, Edición Especial-III Congreso Regional de Economía del Norte Grande-Pág 1-30 URL de la Revista: http://visiondefuturo.fce.unam.edu.ar/index.php/visiondefuturo/index URL del Documento: https://visiondefuturo.fce.unam.edu.ar/index.php/visiondefuturo/issue/view/20 
Además de la dificultad que implica definir el concepto de feminización de la pobreza como lo hacen estos autores, se encuentran también en la literatura controversias al tipo de hogar encabezado por mujeres. Así, por ejemplo, Rajkarnikar \& Ramnarain (2019) distinguen entre jefatura de jure y jefatura de facto, para diferenciar situaciones en las que la jefatura es de carácter estructural y permanente, como la primera, de una coyuntural y transitoria, como la segunda. Ejemplo de casos que caen dentro del primer grupo, aquellos hogares encabezados por mujeres por fallecimiento del cónyuge, mientras que el segundo puedo darse por ausencia debida a migración o desplazamiento no voluntario del cónyuge (refugiados, por ejemplo). ${ }^{4}$

En la Argentina hay muy pocos estudios sobre feminización de la pobreza. González Rosada (2019) muestra que el 37\% de las personas en la Argentina viven en hogares con jefatura femenina, y que esas personas representan al $40 \%$ de las personas pobres del país. También muestra que la prevalencia de la pobreza de las mujeres es más alta que la de los hombres, en particular, en el rango de edad de 35 a 39, cuando en general las mujeres alcanzan el pico de fecundidad: entre los 25 y los 39 años hay, en promedio, 118 mujeres, por cada 100 hombres viviendo en hogares pobres. El análisis de este autor abarca de esta manera las diferentes formas de estimar la diferencia de pobreza en hogares encabezados por hombres y hogares encabezados por mujeres: la representación de personas pobres viviendo en hogares con jefatura femenina y la tasa de prevalencia de la pobreza en hogares encabezados por mujeres. Ambos indicadores reflejan una brecha que resulta desfavorable a las mujeres.

\section{La feminización de la pobreza en la argentina y sus regiones: nivel y tendencias}

Siguiendo lo sugerido en la literatura, en esta sección se analizarán dos indicadores de pobreza según el sexo de la persona de referencia (PR) del hogar: a) la proporción de personas en hogares pobres y no pobres; b) la tasa de prevalencia de la pobreza según el sexo de la PR del hogar. Se evaluará la evolución de ambos indicadores por semestres para el período 2003-2020 tomando el conjunto de jurisdicciones cubiertas por la EPH en cada semestre/año (apartado A); y se hará foco en el primer semestre de 2019 para examinar los diferenciales por regiones (sección $\mathrm{B}$ ). ${ }^{5}$

\footnotetext{
${ }^{4}$ Lo que resulta interesante de esta clasificación de hogares son sus implicancias de política. No se profundiza sobre este tema dado que escapa a los objetivos del presente estudio más bien de carácter introductorio.

${ }^{5}$ La excepción a esta regla es el año 2020 , dado que se cuenta con el dato del primer trimestre solamente. La elección del primer semestre de 2019 se debe a que en el segundo semestre de ese año no se cuenta con información del aglomerado Chaco (ver sección V).

“Visión de Futuro" Año 18, Volumen Nº 25 N², Edición Especial-III Congreso Regional de Economía del Norte Grande-Pág 1-30 URL de la Revista: http://visiondefuturo.fce.unam.edu.ar/index.php/visiondefuturo/index

URL del Documento: https://visiondefuturo.fce.unam.edu.ar/index.php/visiondefuturo/issue/view/20

ISSN 1668 - 8708 - Versión en Línea

E-mail: revistacientifica@fce.unam.edu.ar
} 


\section{A. Nivel y evolución - Argentina}

Actualmente, más del $40 \%$ de la población del país reside en hogares encabezados por mujeres. El Gráfico 1 muestra que ese porcentaje, tanto de personas pobres, como no pobres, fue aumentado a lo largo del tiempo, habiendo registrado su valor más bajo en el segundo semestre del año 2003, donde comienza la serie, con un $25 \%$. Nótese que, en este gráfico, y en todos los que tienen una referencia temporal., aparecen cortes en los años 2007 y 2015 , por la falta de disponibilidad de esa información. Durante ese período el Instituto Nacional de Estadística y Censos (INDEC) estuvo intervenido por el Gobierno Nacional, una de cuyas consecuencias, fue la falta de publicación de los datos del primer y último año de intervención. ${ }^{6}$

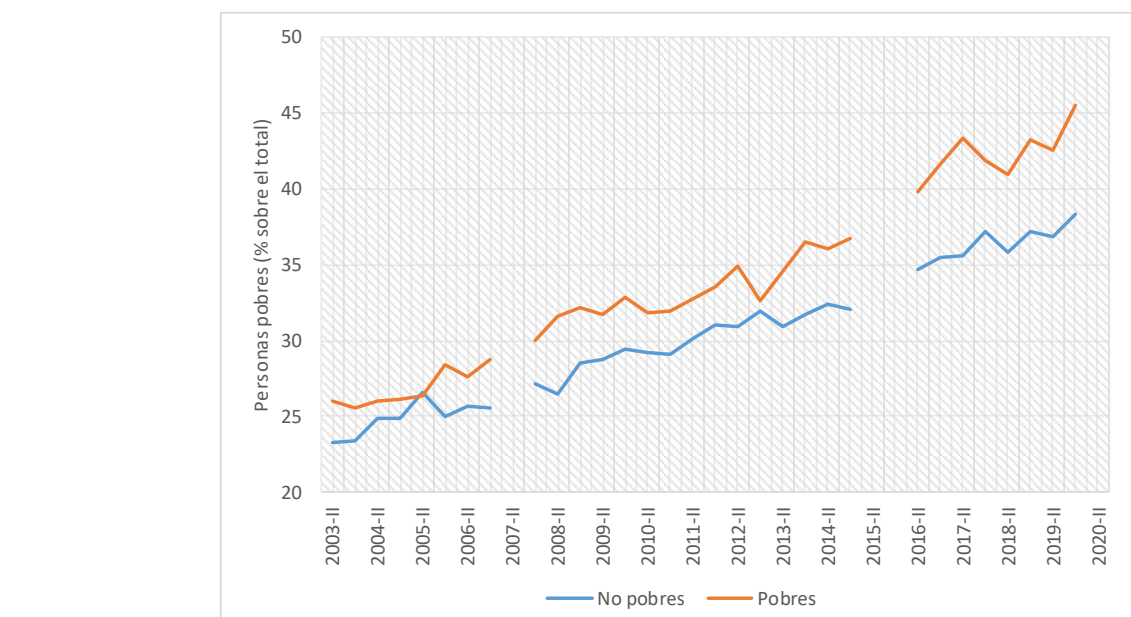

Gráfico $N^{\circ}$ 1: Argentina. Personas que residen en hogares con jefatura femenina según la condición de pobreza del hogar

Fuente: Elaboración propia según datos de INDEC-EPH

A pesar de algunas oscilaciones, probablemente provocadas por temas muestrales, la serie revela un aumento sostenido, sin interrupciones. Debido a que el aumento de la población que reside en hogares pobres creció más que aquella que lo hace en hogares no pobres, queda muy claro también el aumento de la diferencia entre personas pobres y no pobres viviendo en hogares con jefatura femenina. Lo anterior permite afirmar que no sólo hay más personas pobres que no pobres viviendo en hogares encabezados por mujeres, sino que hay evidencias claras de un aumento de la diferencia, lo que implica feminización de la pobreza en la Argentina, al menos durante los últimos 7 años.

Por otra parte, en todos los semestres el período 2003-2020 en la Argentina, los hogares regidos por mujeres tuvieron niveles de pobreza siempre superiores a los hogares regidos por hombres (Gráfico 2). Así, si por feminización de la pobreza se entiende el fenómeno de

\footnotetext{
6 La intervención comenzó con el cambio de las autoridades de la Dirección de Índices de Precios del INDEC: Decreto 100/2007 del Poder ejecutivo Nacional.

"Visión de Futuro" Año 18, Volumen N$^{\circ} 25$ Nº 2, Edición Especial-III Congreso Regional de Economía del Norte Grande-Pág 1-30 URL de la Revista: http://visiondefuturo.fce.unam.edu.ar/index.php/visiondefuturo/index

URL del Documento: https://visiondefuturo.fce.unam.edu.ar/index.php/visiondefuturo/issue/view/20

ISSN 1668 - 8708 - Versión en Línea

E-mail: revistacientifica@fce.unam.edu.ar
} 
aumento de la disparidad de la tasa de pobreza entre hogares regidos por hombres y hogares regidos por mujeres, puede afirmarse que en Argentina se verificó una feminización de la pobreza durante los últimos 7 años. Desde el inicio de la serie y hasta el año 2012, la brecha de pobreza entre hogares con jefatura masculina y hogares con jefatura femenina había oscilado en torno a 3 puntos porcentuales. Luego fue aumentando en los años subsiguientes para ubicarse en un valor de casi 7 puntos porcentuales (más del doble) hacia el final de la serie. Si bien no se cuenta con datos para otros períodos aumentos fuertes y marcado de la pobreza, el Gráfico 2 sugiere que la ampliación de la disparidad coincidió con un período de aumento del nivel general de pobreza del país.

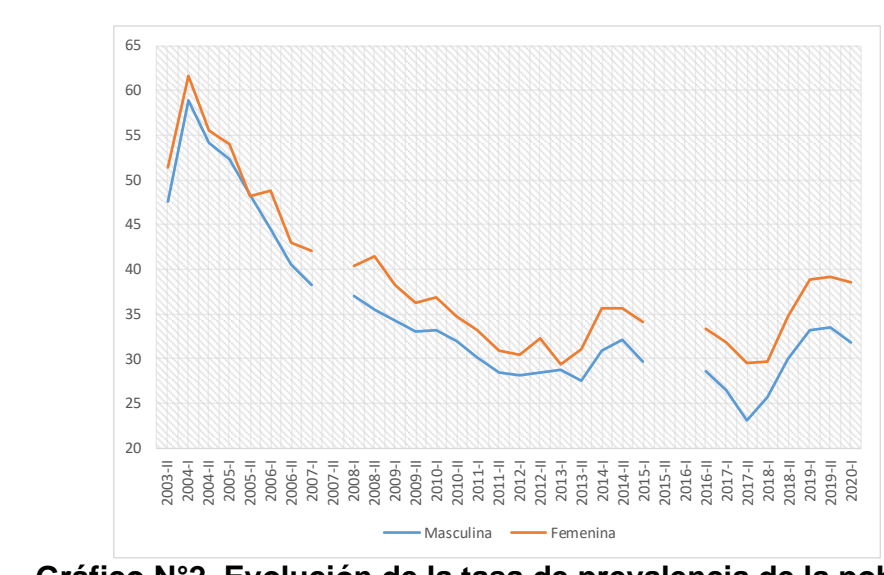

Gráfico N². Evolución de la tasa de prevalencia de la pobreza en la Argentina según el sexo de la PR del hogar

Fuente: Elaboración propia con datos de INDEC-EPH

Este proceso de feminización de pobreza se dio en un contexto de un crecimiento acelerado del porcentaje de personas que viven en hogares liderados por mujeres (Gráfico 1), o que tienen a mujeres como las principales proveedoras del hogar. ${ }^{7}$ Según cálculos propios, mientras que en el primer semestre de 2004 el 24\% de la población argentina vivía en hogares cuyo principal proveedor de ingresos era una mujer, hacia fines de 2019 , dicho porcentaje había aumentado al 36\%, un aumento superior a los 12 puntos porcentuales en un período un poco mayor a los 15 años. No está entre los objetivos de este documento discutir las posibles causas de este fenómeno, pero no cabe duda que combinación entre esta tendencia y la que se muestra en el Gráfico 1 es motivo de reflexión: cada vez más personas viviendo en hogares con jefatura femenina y una brecha de pobreza creciente entre hogares encabezados por mujeres comparada con aquellos con jefatura masculina.

El Gráfico 1 no distingue el tipo de hogar al cual pertenecen hombres y mujeres. Si se centra la atención sólo en los hogares con jefatura femenina, se encuentra una amplia variedad de situaciones en términos de pobreza monetaria. Parece útil distinguir dos grupos:

\footnotetext{
7 No se muestran aquí datos que correlacionan la condición de jefatura con la provisión de ingresos. Los resultados que se obtienen al cambiar la definición de PR no son significativos.

"Visión de Futuro" Año 18, Volumen $N^{\circ} 25$ Nº 2, Edición Especial-III Congreso Regional de Economía del Norte Grande-Pág 1-30 URL de la Revista: http://visiondefuturo.fce.unam.edu.ar/index.php/visiondefuturo/index URL del Documento: https://visiondefuturo.fce.unam.edu.ar/index.php/visiondefuturo/issue/view/20 
los hogares unipersonales y nucleares sin hijos, por un lado, y los hogares nucleares con hijos, monoparentales y extensos, por otro. La pobreza de este último grupo, es entre 4 y 5 veces más elevada que la del primero (Gráfico 3).

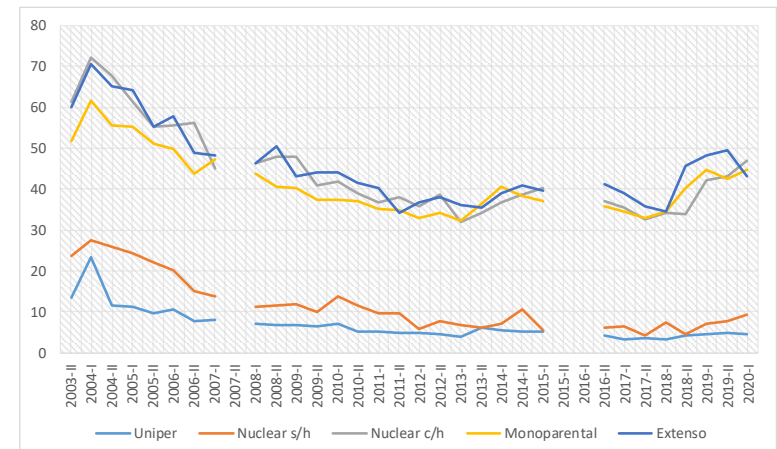

Gráfico $N^{\circ} 3$ : Evolución de la pobreza de hogares con jefatura femenina en la Argentina según tipo de hogar

Fuente: Elaboración propia con datos de INDEC-EPH

La evolución de la pobreza en estos subgrupos parece ser la misma: un descenso generalizado luego de la gran crisis de 2001/02, que se detiene en el año 2013. A partir de ese momento hay una constancia en los niveles que comienza a aumentar en 2018 hasta el final del período. Debido a la crisis económica que trajo como consecuencia la pandemia de COVID-19, el panorama para los años subsiguientes es de un aumento de la pobreza en todos los grupos, lo que significaría una consolidación de la tendencia ascendente que revelan los datos de los gráficos anteriores.

Pero ocurre que si bien los hogares nucleares con hijos, los monoparentales y los extensos liderados por mujeres tienen un nivel similar de pobreza (entre el $40 \%$ y el $50 \%$ de la población de esos hogares es pobre), en términos de disparidad por género no se trata de un grupo homogéneo. Según puede observarse en el Gráfico 4, la brecha mayor en un número importante de períodos corresponde a los hogares monoparentales. Puede decirse que, exceptuando unos pocos años al inicio de la serie, la dominancia de la mayor pobreza femenina en hogares monoparentales se verifica en todo el período, ciertamente con oscilaciones. 


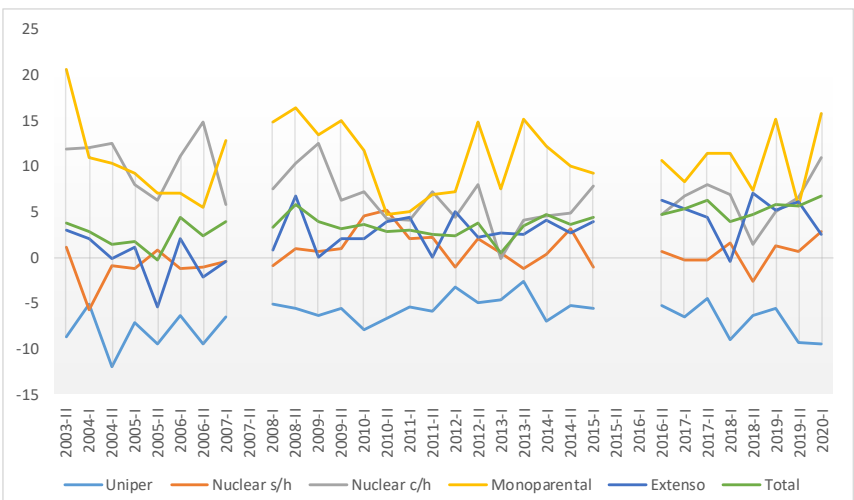

\section{Gráfico $N^{\circ} 4$ : Evolución de la disparidad de tasas de pobreza entre hogares con jefatura femenina y masculina en la Argentina según tipo de hogar Fuente: Elaboración propia con datos de INDEC-EPH}

Esto justifica el centrar el análisis de la brecha por género, principalmente en los hogares monoparentales y extensos. La pregunta acerca de la razón que explica esta mayor pobreza femenina cobra singular importancia en este contexto. Si se observa con atención el Gráfico 3, se infiere que la mayor parte de los años la brecha se sitúa por sobre los 10 puntos porcentuales. Los años en los que la disparidad perfora ese piso corresponden a la entrada en vigencia en el año 2009 del Programa Asignación Universal por Hijo para la Protección Social (AUH) y a los años de mayor impacto, que son los inmediatos subsiguientes: 2010 y 2011.

\section{B. Regiones}

Argentina tiene una estructura económica y productiva fuertemente heterogénea a nivel regiones. Esto se refleja en indicadores diversos, entre los que están los sociales. Entre tales indicadores, la pobreza monetaria arroja una desigualdad regional muy marcada. Las regiones que componen el Norte Grande del país, el Nordeste y el Noroeste (NEA y NOA, respectivamente) son las que revelan niveles de pobreza monetaria más elevados. Las últimas cifras disponibles dan cuenta de esta disparidad geográfica: mientras la pobreza para el conjunto de centros urbanos que releva la Encuesta Permanente de Hogares (EPH) fue del $34,6 \%$, la del NOA fue del 37,4\% y la del NEA del $40,2 \%$. Esta desigualdad territorial es estructural y se verifica también cuando se usan indicadores de calidad de vida no monetarios y para otros momentos del tiempo (Paz, 2019).

Más específicamente centrado en el problema que se aborda en este documento, las regiones NEA y NOA arrojan no solamente un porcentaje mayor de personas viviendo en hogares encabezados por mujeres, sino que la diferencia es mayor en el porcentaje de personas que viven en hogares pobres encabezados por mujeres. Frente a una media

\footnotetext{
“Visión de Futuro" Año 18, Volumen N²5 N², Edición Especial-III Congreso Regional de Economía del Norte Grande-Pág 1-30 URL de la Revista: http://visiondefuturo.fce.unam.edu.ar/index.php/visiondefuturo/index URL del Documento: https://visiondefuturo.fce.unam.edu.ar/index.php/visiondefuturo/issue/view/20 
nacional del $43 \%$ para el primer semestre de 2019, las regiones NEA y NOA se aproximaron al 46\% (Gráfico 5).

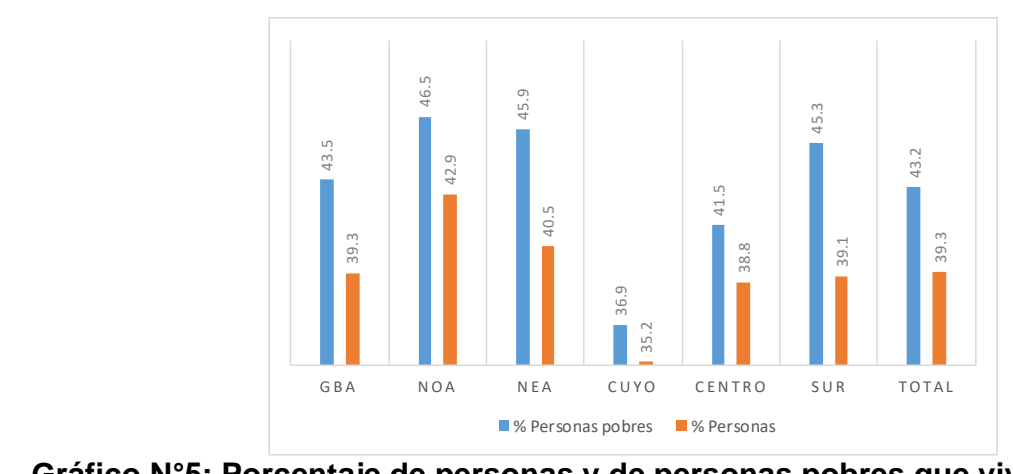

Gráfico $N^{\circ} 5$ : Porcentaje de personas y de personas pobres que viven en hogares con jefatura femenina. Argentina, 2019

Fuente: Elaboración propia con datos de INDEC, EPH

En el gráfico anterior no se diferencia por tipo de hogares. Hay que tener en cuenta que los tamaños de muestra no son lo suficientemente grandes como para soportar demasiadas aperturas de variables. Hecha esta advertencia, en el Cuadro 1 se ha calculado la tasa de pobreza en hogares monoparentales según I sexo de la PR para las distintas regiones del país.

Cuadro 1. Prevalencia de pobreza en hogares monoparentales. Argentina y regiones, primer semestre de 2019 (\% de personas)

\begin{tabular}{|c|c|c|c|c|c|c|c|}
\hline \multirow[b]{2}{*}{ Sexo PR } & \multirow[b]{2}{*}{ GBA } & \multirow[b]{2}{*}{ NOA } & \multirow[b]{2}{*}{ NEA } & \multicolumn{2}{|r|}{ Centr } & \multirow[b]{2}{*}{ Sur } & \multirow[b]{2}{*}{ Total } \\
\hline & & & & Cuyo & 0 & & \\
\hline & & & & & 37.0 & 17.2 & \\
\hline Varón & $25.8 \%$ & $32.2 \%$ & $41.2 \%$ & $26.9 \%$ & $\begin{array}{r}\% \\
42.9\end{array}$ & $\begin{array}{r}\% \\
37.5\end{array}$ & $29.5 \%$ \\
\hline Mujer & $48.0 \%$ & $34.3 \%$ & $49.5 \%$ & $40.4 \%$ & $\begin{array}{r}\% \\
41.9\end{array}$ & $\begin{array}{r}\% \\
34.3\end{array}$ & $44.7 \%$ \\
\hline Total & $44.7 \%$ & $34.0 \%$ & $48.4 \%$ & $38.5 \%$ & $\%$ & $\%$ & $42.4 \%$ \\
\hline Diferenci & 22.2 & 2.1 & 8.2 & 13.5 & 5.9 & 20.4 & 15.1 \\
\hline
\end{tabular}

Puede observarse la situación particular del NEA y del NOA: la disparidad entre géneros es notablemente más baja que el promedio nacional. La diferencia entre tasas de pobreza a nivel nacional está claramente influenciada por la situación del GBA, que registra una baja tasa de pobreza en hogares encabezados por hombres y la segunda tasa más elevada en hogares encabezados por mujeres del país. En estos casos queda claro que la pregunta acerca de las razones de esta paradoja de las regiones NEA y NOA (regiones con alta pobreza y baja disparidad de género) debería apuntar a explicar la diferencia entre regiones de tasas de pobreza en hogares monoparentales encabezados por hombres, por un lado y de hogares monoparentales encabezados por mujeres, por otro. Es probable que esta diferencia esté influenciada por temas muestrales, así que en lo subsiguiente se trabajará con hogares encabezados por mujeres sin diferenciar el tipo de hogar de que se trata.

\footnotetext{
"Visión de Futuro" Año 18, Volumen $N^{\circ} 25$ Nº 2, Edición Especial-III Congreso Regional de Economía del Norte Grande-Pág 1-30 URL de la Revista: http://visiondefuturo.fce.unam.edu.ar/index.php/visiondefuturo/index URL del Documento: https://visiondefuturo.fce.unam.edu.ar/index.php/visiondefuturo/issue/view/20 ISSN 1668 - 8708 - Versión en Línea 


\section{Datos y método}

Esta sección se ocupa de los datos que se usarán para contrastar la feminización de la pobreza en la Argentina y en la región del NGA, luego de controlados los grandes grupos de determinantes profundos: factores individuales, familiares, laborales la carga demográfica en cada uno de esos hogares.

\section{A. Origen de los datos}

Los datos provienen de la Encuesta Permanente de Hogares (EPH), relevamiento realizado por el Instituto Nacional de Estadística y Censos (INDEC), con la colaboración de las direcciones provinciales de estadística. La EPH se aplica en la Argentina desde el año 1973 a través de la medición puntual de dos ondas anuales (mayo y octubre). A partir de 2003, la EPH pasó a ser un relevamiento continuo (EPHC) que produce datos con frecuencia trimestral. La muestra en la que se basa es probabilística, estratificada, en dos etapas de selección, está distribuida a lo largo del período respecto del cual se brinda información (el trimestre) y el relevamiento se desarrolla durante todo el año.

Con una muestra trimestral típica es de un poco más de 26 mil viviendas, la EPH produce estimaciones trimestrales válidas para un conjunto de los 31 aglomerados urbanos (también llamados "centros urbanos") agrupados en seis regiones estadísticas: Gran Buenos Aires, Nordeste, Noroeste, Centro y Sur (o Patagonia). Para las estimaciones que siguen se ha usado la muestra correspondiente al primer semestre de 2019. Siguiendo la tradición de INDEC de calcular la pobreza monetaria de manera semestral se eligió este conjunto de datos por el ser el más reciente disponible. Téngase en cuenta que no hay información de la ciudad de Resistencia para el tercer trimestre de 2019, con lo cual resulta imposible construir el segundo semestre de ese año, y los datos del 2020 cubren sólo el primer trimestre.

\section{B. Definiciones operativas}

Medeiros \& Costa (2008) plantean cuatro posibles formas de definir feminización de pobreza. Si el foco se pone en la diferencia entre hombres y mujeres, la feminización de la pobreza se puede definir como: a) un aumento de los niveles absolutos de pobreza entre las mujeres; o b) por un aumento en la diferencia en los niveles de pobreza entre mujeres y hombres. Por su parte, si el foco se centra en los hogares encabezados por mujeres y hombres, la feminización de la pobreza se puede definir como a) un aumento de los niveles absolutos de pobreza entre los hogares encabezados por mujeres; b) un aumento en la diferencia en los niveles de pobreza entre los hogares encabezados por mujeres y entre los hogares encabezados por hombres y por parejas. En este trabajo se sigue una variante del “Visión de Futuro" Año 18, Volumen No 25 N 2, Edición Especial-III Congreso Regional de Economía del Norte Grande-Pág 1-30 URL de la Revista: http://visiondefuturo.fce.unam.edu.ar/index.php/visiondefuturo/index URL del Documento: https://visiondefuturo.fce.unam.edu.ar/index.php/visiondefuturo/issue/view/20 
indicador que sugiere esta última definición: diferencia en los niveles de pobreza entre hogares encabezados por mujeres y hogares encabezados por hombres, que es la tendencia que se mostró en el Gráfico 1.

La elección del tipo de hogar encabezado por mujeres no es un tema menor como se vio en la sección III. Este documento se centra en los hogares monoparentales, con jefatura femenina. En este trabajo se entiende por hogar monoparental un hogar compuesto por una PR, que no tiene cónyuge y que tiene hijos. Como lo sostiene Mazzeo (2008), la expresión hogar monoparental puede referirse a realidades distintas: un hogar formado exclusivamente por un núcleo conyugal monoparental formado por padre o madre con sus hijos (nuclear monoparental) o un hogar en el que además del núcleo conyugal monoparental se encuentran otras personas, parientes o no (no nuclear monoparental). Los distintos tipos de hogar se diferencian por sexo del jefe y se destaca que para investigar la importancia de los hogares monoparentales se calcula su participación en el total de hogares conyugales.

Se trabaja aquí trabajar sólo con pobreza monetaria, a diferencia del trabajo previo (Arévalo \& Paz, 2016) que observaba con detalle la pobreza en otras dimensiones no monetaria de las privaciones. Se considerará pobre a un hogar cuyos ingresos no resultan suficientes para cubrir los gastos que demanda una canasta básica de bienes alimentarios y no alimentarios. El utilizar al hogar y no al individuo como unidad de análisis trae aparejados un sinnúmero de problemas reconocidos en la literatura sobre los estudios de pobreza y particularmente relevantes para el tema de la feminización de la pobreza. Por ejemplo, se supone una distribución igualitaria del ingreso entre todos los miembros del hogar, no se conoce cómo se realizan las transferencias de ingresos entre los miembros o si la mujer jefa tiene el control efectivo de los ingresos. Esto por considerar sólo algunos, además de que la pobreza de las mujeres se extiende más allá de los hogares pobres, considerando que también que podría afectar a una proporción importante de hogares no pobres.

Dado que la variable principal de estudio es la condición de pobreza del hogar, el ingreso familiar juega un rol central en la determinación de su valor. Cabe entonces aclarar que se respetaron las decisiones oficiales de los datos. Se trabajó con los ponderadores que corrigen por no respuesta los ingresos totales del hogar. ${ }^{8}$

\section{Estrategia metodológica}

Se estiman regresiones logísticas con el propósito de analizar la relación entre la pobreza en hogares con jefatura femenina y las variables con las que se presume ésta está

\footnotetext{
8 Para detalles acerca de la manera que tiene INDEC de corregir por no respuesta puede consultarse INDEC (2020b).

"Visión de Futuro" Año 18, Volumen N$^{\circ} 25$ Nº 2, Edición Especial-III Congreso Regional de Economía del Norte Grande-Pág 1-30 URL de la Revista: http://visiondefuturo.fce.unam.edu.ar/index.php/visiondefuturo/index

URL del Documento: https://visiondefuturo.fce.unam.edu.ar/index.php/visiondefuturo/issue/view/20

ISSN 1668 - 8708 - Versión en Línea

E-mail: revistacientifica@fce.unam.edu.ar
} 
correlacionada. Las variables de control incluidas en los modelos correspondientes a la PR del hogar fueron clasificadas en cuatro grandes grupos: a) individuales: edad, nivel educativo; b) del hogar: unipersonal, nuclear (con uy sin hijos), monoparental y extenso; c) de la situación conyugal: soltera, casada, separada, viuda; d) carga demográfica: niñas y niños (0 a 17 años) y personas mayores (65 años y más); y e) situación laboral: asalariada (formal y no formal), cuenta propia (profesional y no profesional), desocupada y estadísticamente inactiva . De estos grupos, los que tienen que ver de manera directa con la pobreza son los dos últimos: el tamaño y la composición del hogar de personas no potencialmente activas y la situación laboral de la PR.

Los modelos estimados responden a la siguiente especificación:

$$
\mathrm{Y}_{\mathrm{ij}}=\beta_{1} \text { Condac }_{\mathrm{ij}}+\beta_{2} \mathrm{TCH}_{\mathrm{ij}}+\mathrm{X} \Theta+\mathrm{u}_{\mathrm{ij}}
$$

donde $Y_{i j}$ representa la probabilidad de pobreza del hogar "i" en la región "j". La variable Condac $_{\mathrm{ij}}$ es una variable ficticia que indica la condición de actividad de la PR y $\mathrm{TCH}_{\mathrm{ij}}$ el tamaño y composición de los hogares. Por su parte, $\mathrm{X}$ es una matriz que además de una columna de números 1 contiene las variables de control. Por otro lado, $\beta$ y $\Theta$ son los parámetros, y $u_{i j}$, el término de error, que se supone normalmente distribuido, con media 0 y varianza constante.

Los resultados de las estimaciones se presentan en términos de razón de probabilidades u odds ratios (OR).

Regresiones estimadas

Para la identificación del efecto neto de cada variable sobre el fenómeno analizado se estimarán dos grupos de regresiones: a) en el primero se tendrá como variable dependiente el sexo de la PR y se utilizarán datos solamente de la población identificada como pobre por ingresos del hogar. El procedimiento para identificar hogares y personas pobres es el estándar oficial de la Argentina (INDEC, 2016); b) en segundo se usará como variable del lado izquierdo la condición de pobreza de la persona (captada a través del hogar) y se estimará usando datos de hogares encabezados por mujeres solamente. Lo de grupos de regresiones alude a que se estiman dos regresiones para a) y dos para b), una que toma los datos para el conjunto de aglomerados urbanos relevados por la EPH y otra solamente los centros urbanos que conforman la región del NGA: Catamarca, Corrientes, Resistencia, San Salvador de Jujuy y Palpalá, Salta, Santiago del Estero y La Banda, Tucumán.

Descomposición de las diferencias

Con las regresiones comentadas en el acápite anterior, se descompondrá la diferencia de pobreza regional, tomando para ello, dos grupos de aglomerados: uno que incluirá a todos los centros urbanos menos a los de la región del NGA y los que componen la región del NGA

\footnotetext{
“Visión de Futuro" Año 18, Volumen N²5 N², Edición Especial-III Congreso Regional de Economía del Norte Grande-Pág 1-30 URL de la Revista: http://visiondefuturo.fce.unam.edu.ar/index.php/visiondefuturo/index

URL del Documento: https://visiondefuturo.fce.unam.edu.ar/index.php/visiondefuturo/issue/view/20 
(RESTO). En términos más formales y siguiendo la versión no lineal del método de Blinder (1973) y Oaxaca (1973), dicha descomposición puede escribirse de la siguiente manera:

$$
\begin{aligned}
& \overline{\mathrm{Y}}^{\mathrm{NGA}}-\overline{\mathrm{Y}}^{\mathrm{RESTO}}=\left[\sum_{\mathrm{i}=1}^{\mathrm{N}^{\mathrm{NGA}}} \frac{\mathrm{F}\left(\mathrm{x}_{\mathrm{i}}^{\mathrm{NGA}} \hat{\beta}^{\mathrm{NGA}}\right)}{\mathrm{N}^{\mathrm{NGA}}}-\sum_{i=1}^{\mathrm{N}^{\text {RESTO }}} \frac{\mathrm{F}\left(\mathrm{x}_{\mathrm{i}}^{\mathrm{RESTO}} \hat{\beta}^{\mathrm{NGA}}\right)}{\mathrm{N}^{\mathrm{RESTO}}}\right] \\
& +\left[\sum_{i=1}^{\mathrm{N}^{\text {RESTO }}} \frac{\mathrm{F}\left(\mathrm{x}_{\mathrm{i}}^{\mathrm{RESTO}} \hat{\beta}^{\mathrm{NGA}}\right)}{\mathrm{N}^{\text {RESTO }}}-\sum_{\mathrm{i}=1}^{\mathrm{N}^{\text {RESTO }}} \frac{\mathrm{F}\left(\mathrm{x}_{\mathrm{i}}^{\mathrm{RESTO}} \hat{\beta}^{\text {RESTO }}\right)}{\mathrm{N}^{\text {RESTO }}}\right]
\end{aligned}
$$

donde $\overline{\mathrm{Y}}^{\mathrm{NGA}}$ e $\overline{\mathrm{Y}}^{\mathrm{RESTO}}$ representan las tasas de prevalencia de la pobreza en hogares con jefatura femenina en distintas regiones respectivamente; $\mathrm{N}^{\mathrm{NGA}}$ y $\mathrm{N}^{\mathrm{RESTO}}$, la población femenina en las regiones NGA y RESTO. También se realizan comparaciones entre el grupo de hogares con jefatura masculina y femenina, dentro de la misma región.

El primer término del lado derecho representa la parte de la brecha que se debe a diferencias de características entre los grupos (también llamada "parte explicada" de la brecha), y el segundo término captura la parte atribuible a diferencias de comportamiento (también denominadas aquí diferencias de propensión o "parte no explicada").

Este tipo de descomposición es sensible al denominado "problema de los números índice"; es decir, el resultado varía según se use como grupo de comparación a los hombres, a las mujeres o a ambos. En este estudio se empleó la alternativa propuesta por Oaxaca y Ransom (1994), basada en que, como ponderadores para el primer término de la descomposición (los $\beta^{\mathrm{H}}$ de la expresión anterior), se utilizan los coeficientes estimados a partir de una muestra conjunta de los dos grupos.

La metodología descrita se centra específicamente en el segundo término del lado derecho de la descomposición propuesta en la ecuación anterior, que cuantifica la contribución que hace la distinta propensión a participar de cada grupo a la brecha total. Usando como ponderadores los coeficientes estimados de una regresión probit basada en la muestra agrupada, se puede examinar la contribución de cada variable o cada grupo de variables a la brecha entre géneros de las tasas de participación en la fuerza laboral. La misma metodología se aplica para tratar las diferencias en la proporción de tiempo que hombres y mujeres emplean en tareas domésticas no remuneradas.

\section{Resultados}

\section{Aproximación descriptiva}

En la Tabla A.1 del Apéndice se reportan los resultados descriptivos de la muestra utilizada. Dicha tabla, al igual que la que contiene los resultados de la regresión logística (Tabla A.2) consta de cuatro columnas: las dos primeras examinan el primer indicador de "Visión de Futuro" Año 18, Volumen N$^{\circ} 25$ N² 2, Edición Especial-III Congreso Regional de Economía del Norte Grande-Pág 1-30 URL de la Revista: http://visiondefuturo.fce.unam.edu.ar/index.php/visiondefuturo/index URL del Documento: https://visiondefuturo.fce.unam.edu.ar/index.php/visiondefuturo/issue/view/20 
feminización de pobreza, el porcentaje de personas pobres que residen en hogares encabezados por mujeres, y las dos siguientes, la tasa de pobreza. La diferencia entre la primera y la segunda y la tercera y cuarta columnas tiene que ver con las jurisdicciones incluidas en el análisis: las columnas [1] y [3] contienen los datos del conjunto de centros urbanos revelados por la EPH, mientras que la [2] y la [4] se refieren al Norte Grande de Argentina (NGA).

En la primera fila de la Tabla A.1 se muestran los indicadores que se analizaron en la sección anterior. En las filas siguientes están todas las variables que se suponen están correlacionadas con la pobreza en general y con la feminización de la pobreza en particular, según se ha marcado en la sección II (marco conceptual). De los resultados de la primera fila se desprende que la feminización de la pobreza es mayor en el NGA y que es mayor aún si se usa como parámetro la tasa de pobreza. También puede constatarse que los hogares pobres del NGA presentan mayores desventajas en términos de dotaciones: un nivel educativo más bajo, mayor cantidad de niñas y niños en los hogares, aunque menos personas mayores, una mayor proporción de hogares extensos, una proporción mayor de solteras entre las PR, y un poco más de inactividad estadística de la población. Se aprecia también que alrededor del $12 \%$ de los hogares pobres están localizados en la región del NGA.

Si la atención se centra sólo en los hogares con jefatura femenina (columnas [3] y [4]) se observa que las diferencias en esas variables entre el total de aglomerados y el NGA son todavía más marcadas. Si bien el nivel educativo es más elevado (nótese que se están incluyendo hogares pobres y no pobres en este caso, mientras que en la comparación anterior sólo participaban hogares pobres), se aprecian más niñas y niños en los hogares, más viudas y solteras y bastante más inactivas estadísticas. Además, un poco más del $10 \%$ de los hogares con jefatura fémina están localizados en el NGA.

Ambas circunstancias hacen que, en términos descriptivos, la pobreza esperada de los hogares del NGA sea mayor que la del resto del país. Son muy pocas las variables en las que esta región iguala los niveles que alcanza en los centros urbanos tomados como un todo. ${ }^{9}$

\section{Análisis condicional}

La casi totalidad de los indicadores incluidos como determinantes de la pobreza fueron significativos y actuaron en la dirección prevista. En la Tabla A.2 se reportan los OR de las regresiones logísticas estimadas. Como se explicó antes, las dos primeras columnas trabajan

${ }^{9}$ Se debe tener en cuenta que todas las jurisdicciones, incluye al norte grande también. Esta advertencia es importante porque en las descomposiciones, se separa a estas regiones del resto.

“Visión de Futuro" Año 18, Volumen No 25 Nº 2, Edición Especial-III Congreso Regional de Economía del Norte Grande-Pág 1-30 URL de la Revista: http://visiondefuturo.fce.unam.edu.ar/index.php/visiondefuturo/index

URL del Documento: https://visiondefuturo.fce.unam.edu.ar/index.php/visiondefuturo/issue/view/20

ISSN 1668 - 8708 - Versión en Línea

E-mail: revistacientifica@fce.unam.edu.ar 
con el indicador 1 (porcentaje de personas pobres e hogares con jefatura femenina) y las dos últimas columnas, la tasa de pobreza en hogares con jefatura femenina.

Entre las personas pobres aumenta la probabilidad de residir en un hogar con jefatura femenina un nivel educativo más alto de la PR, el tener hijas e hijos adolescentes a cargo, en residir en hogares monoparentales o extensos (más en los primeros que en los segundos), el ser una asalariada/o informal, desempleada/o, e inactiva/o. La situación en NGA (columna 2) no difiere del conjunto de regiones, excepto en algunos parámetros. Por ejemplo, es llamativo las chances de las personas mayores pobres aumenta la probabilidad de residir en un hogar con una mujer como cabeza de familia. También el ser viuda o soltera es más relevante en el NGA que en el conjunto de aglomerados.

Por su parte, entre las personas que habitan en hogares comandados por mujeres se observa que la educación de la mujer jefa de hogar reduce la probabilidad de ser pobre. Aumentan las chances de pobreza niñas y niños de todos los grupos de edad y el efecto es creciente con la edad de las niñas y niños. La presencia de personas mayores en estos hogares reduce la probabilidad de ser pobre. Tiene un impacto muy fuerte y positivo sobre la pobreza, el residir en un hogar monoparental o extenso, resultado que no se mantiene para el NGA, donde la pobreza de estos hogares es más baja que la de los hogares nucleares con hijos (grupo de referencia). La situación conyugal y la laboral, son importantes para explicar la pobreza en hogares con jefatura femenina.

\section{Descomposición}

Para separar los efectos de las diferencias reflejadas en la Tabla A.1 (descriptivos) y la Tabla A.2 (parámetros estimados) se procedió a descomponer las diferencias de los indicadores de pobreza en HJF entre la región NGA y el resto de centros urbanos. En el Cuadro 2 se muestra el primer ejercicio de descomposición. Las dos primeras filas muestran los indicadores en ambos conjuntos de ciudades, la tercera la diferencia observada y las dos últimas la descomposición de esos factores en una parte explicada (dotaciones, Tabla A.1) y en otra parte no explicada (debida a diferencias en los parámetros, Tabla A.2). 
Cuadro 2. Descomposición de la diferencia entre NGA y resto del país de pobreza en HJF

\begin{tabular}{|c|c|c|c|c|}
\hline \multirow[b]{2}{*}{ Componente } & \multicolumn{2}{|c|}{ Indicador 1} & \multicolumn{2}{|c|}{ Indicador 2} \\
\hline & Diferencias & $\begin{array}{l}\text { Descompos } \\
\text { ición }\end{array}$ & Diferencias & $\begin{array}{l}\text { Descompos } \\
\text { ición }\end{array}$ \\
\hline NGA & $\begin{array}{l}0.463^{* \star \star} \\
(0.005)\end{array}$ & & $\begin{array}{l}0.450^{* \star *} \\
(0.004)\end{array}$ & \\
\hline Resto & $0.424^{\star \star \star *}$ & & $0.373^{\star \star *}$ & \\
\hline Argentına & $(0.005)$ & & $(0.005)$ & \\
\hline Diferencia & $\begin{array}{l}0.039^{* * *} \\
(0.007)\end{array}$ & & $\begin{array}{l}0.077^{\star \star *} \\
(0.007)\end{array}$ & \\
\hline $\begin{array}{l}\text { Diferencia } \\
\text { debida a: }\end{array}$ & & & & \\
\hline Dotaciones & & $\begin{array}{l}0.070^{* * *} \\
(0.005)\end{array}$ & & $\begin{array}{l}0.069^{* * *} \\
(0.005)\end{array}$ \\
\hline Parámetros & & $\begin{array}{l}-0.031^{* * *} \\
(0.006)\end{array}$ & & $\begin{array}{l}0.008 \\
(0.007)\end{array}$ \\
\hline Observaciones & 37,071 & 37,071 & 40,016 & 40,016 \\
\hline
\end{tabular}

Nota: Significativamente diferente de cero al $^{* \star *} 1 \%$. La ausencia de asterisco implica que no se rechaza la hipótesis nula. Entre paréntesis se reportan los desvíos estándar (valores absolutos).

Fuente: Elaboración propia con datos de INDEC-EPH, primer semestre de 2019

El segundo indicador da cuenta de una disparidad mayor. Así mientras el porcentaje de personas pobres que residen en hogares con jefatura femenina es 4 puntos porcentuales más alto en el conjunto RESTO que en NGA, la prevalencia de la pobreza en hogares encabezados por mujeres es casi 8 puntos más alto en NGA vis a vis con RESTO. Aquí las diferencias son aún mayores que las reportadas en la Tabla A.1, dado que RESTO excluye a NGA.

La pregunta que se impone aquí es ¿hay mayor feminización de pobreza en el NGA que en RESTO? Si en este caso por feminización de pobreza se entiende a diferencias atribuibles al género para la variable independiente, mayor pobreza en hogares regidos por mujeres, el Cuadro 2 permite una respuesta negativa: toda la diferencia observada de pobrezas femeninas entre RESTO y NGA se debe a la situación de desventaja que enfrentan las mujeres, mayor en NGA que en resto. La parte no explicada es negativa en el primer caso (la diferencia debería ser inversa por los parámetros) y no significativa en el segundo. Cobran relevancia entonces todas las disparidades que se habían marcado al analizar los datos de la Tabla A.1.

La segunda pregunta altamente relevante en el presente contexto es ¿cuáles de esos factores es el más importante de todos? La respuesta está contenida en el Gráfico 6. 


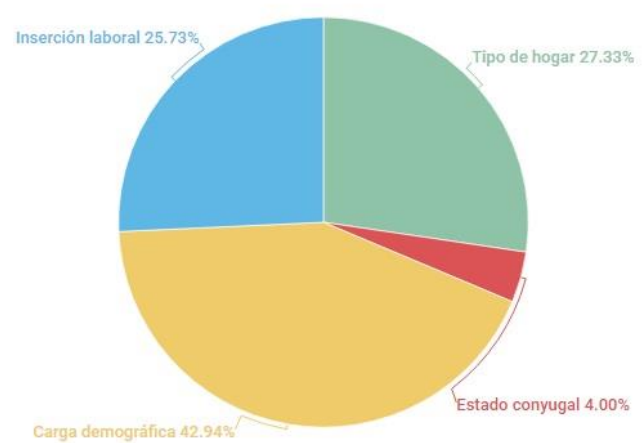

Gráfico $\mathrm{N}^{\circledR} 6$ : Contribución de grupos de factores a la disparidad de pobreza en hogares con jefatura femenina entre el NGA y el resto del país

Fuente: Elaboración propia con datos de INDEC-EPH

Es interesante constatar que los factores conyugales, mencionados en la literatura como altamente relevantes para juzgar las diferencias de pobreza entre hogares encabezados por hombres y hogares encabezados por mujeres, tienen una importancia marginal para explicar las diferencias regionales en la Argentina. La carga demográfica se impone como el determinante más importante, siguiéndoles, en orden de prelación y con importancia casi similar, la inserción laboral y el tipo de hogar. Nótese que no están incluidos aquí los factores individuales, dado que su peso ha sido no significativo.

\section{CONCLUSIÓN}

El objetivo de este documento fue el de evaluar la existencia de feminización de pobreza en la Argentina y de analizar las diferencias de este fenómeno a nivel agregado con la observada en la región NGA, donde los niveles de pobreza monetaria general son los más elevados del país. La pobreza en la Argentina ha descendido ostensiblemente desde los valores elevados que alcanzó durante la crisis de 2001/02. Cayó hasta aproximadamente fines del año 2012, momento a partir del cual se mantuvo en niveles elevados (entre el 25y el 30\%), para registrar una nueva tendencia creciente (situándose en el rango entre 30 y $35 \%$ ) que aumentaría más como consecuencia de la crisis económica ocasionada por la pandemia del coronavirus.

Con este contexto como cuadro de situación se observaron, entre 2003 y 2020, los siguientes patrones: a) aumentó el número de personas que residen en hogares encabezados por mujeres; b) aumentó más el porcentaje de personas pobres que residen en hogares encabezados por mujeres; c) si bien declinó la tasa de prevalencia de la pobreza al principio del período, cuando la declinación cesó, comenzó a aumentar más la prevalencia de la pobreza en HJF comparados con los HJM; d) la región NGA revela mayor pobreza femenina, 
tanto la medida con los indicadores anteriores como por la tasa de prevalencia de la pobreza, especialmente este último.

Del análisis condicional surgen como elementos que explican la mayor pobreza en hogares encabezados por mujeres la cantidad de niñas, niños y personas mayores en los hogares, el tipo de hogar (principalmente monoparental y extenso), la situación conyugal de la PR y la relación que ésta tiene con el mercado laboral. Se constató que, exceptuando algunas variables muy específicas, estos factores operan con intensidad similar tanto en el conjunto de centros urbanos captados por la EPH, como en el NGA.

Este último hallazgo se terminó de verificar al realizar la descomposición de las diferencias en las tasas de pobreza fémina antes mencionadas. Toda la diferencia entre los dos grupos considerados se explica por diferentes dotaciones, queriendo significar con ello que la pobreza femenina es mayor en el NGA porque las mujeres jefas de hogar residen en hogares extensos, tienen más niñas y niños a cargo y una inserción más débil y precaria en el mercado de trabajo. Principalmente se observa una proporción muy elevada de mujeres estadísticamente inactiva en el conjunto de población.

El tema de la feminización de la pobreza en la Argentina requiere de más investigación. El presente es sólo un texto introductorio que destaca la existencia del fenómeno, y las diferencias por regiones. El tema es en sí importante dado que se trata de un fenómeno que conjuga otros dos que alteran el bienestar de la población: el de la pobreza propiamente dicho y la desigualdad de género. Por lo que pudo observarse, los programas focalizados de transferencias de ingresos como se aplican en América Latina en general y en la Argentina en particular, están en la dirección correcta al priorizar a las mujeres como principales destinatarias. No obstante, sería conveniente averiguar a qué se debe el aumento tanto de los hogares regidos por mujeres sino de la pobreza creciente en estos hogares, fenómeno conocido como de feminización de la pobreza. Ese será el próximo paso de nuestros estudios.

\footnotetext{
“Visión de Futuro" Año 18, Volumen N²5 N², Edición Especial-III Congreso Regional de Economía del Norte Grande-Pág 1-30 URL de la Revista: http://visiondefuturo.fce.unam.edu.ar/index.php/visiondefuturo/index

URL del Documento: https://visiondefuturo.fce.unam.edu.ar/index.php/visiondefuturo/issue/view/20

ISSN 1668 - 8708 - Versión en Línea

E-mail: revistacientifica@fce.unam.edu.ar
} 


\section{APÉNDICE DE TABLAS}

Tabla A.1. Valores promedio de las variables incluidas en los análisis

\begin{tabular}{|c|c|c|c|c|}
\hline \multirow[b]{2}{*}{ Variable/Categoría } & \multicolumn{2}{|c|}{ Sólo hogares pobres } & \multicolumn{2}{|c|}{ Sólo HJF } \\
\hline & Todas & $\begin{array}{l}\text { Norte } \\
\text { Grande }\end{array}$ & Todas & $\begin{array}{l}\text { Norte } \\
\text { Grande }\end{array}$ \\
\hline & [1] & [2] & [3] & [4] \\
\hline Indicador de pobreza & 0.432 & 0.463 & 0.389 & 0.451 \\
\hline Edad de la PR (años) & 46.3 & 47.2 & 51.3 & 51.9 \\
\hline \multicolumn{5}{|l|}{ Educación de la PR (dummies) } \\
\hline \multicolumn{5}{|l|}{$\begin{array}{l}\text { Menos que primaria (grupo de } \\
\text { referencia) }\end{array}$} \\
\hline Entre 7 y 11 años de escolaridad & 0.515 & 0.479 & 0.366 & 0.359 \\
\hline 12 años de escolaridad o más & 0.374 & 0.407 & 0.549 & 0.544 \\
\hline \multicolumn{5}{|l|}{ Niñas/os y personas mayores (cantidad) } \\
\hline Niñas/os 0-4 & 0.533 & 0.575 & 0.351 & 0.448 \\
\hline Niñas/os 5-12 & 1.009 & 1.015 & 0.598 & 0.701 \\
\hline Niñas/os 13-17 & 0.633 & 0.726 & 0.413 & 0.487 \\
\hline Persona mayor 65-69 & 0.068 & 0.070 & 0.100 & 0.117 \\
\hline Persona mayor 75-79 & 0.061 & 0.058 & 0.137 & 0.133 \\
\hline Persona mayor 80 o más & 0.029 & 0.023 & 0.084 & 0.066 \\
\hline \multicolumn{5}{|l|}{ Tipo de hogar } \\
\hline \multicolumn{5}{|l|}{$\begin{array}{l}\text { Nuclear con hijas/os (grupo de } \\
\text { referencia) }\end{array}$} \\
\hline Unipersonal & 0.013 & 0.010 & 0.099 & 0.058 \\
\hline Nuclear sin hijas/os & 0.017 & 0.014 & 0.063 & 0.025 \\
\hline Monoparental & 0.125 & 0.101 & 0.225 & 0.217 \\
\hline Extenso & 0.351 & 0.464 & 0.344 & 0.497 \\
\hline \multicolumn{5}{|l|}{ Estado conyugal de la PR (dummies) } \\
\hline \multicolumn{5}{|l|}{ Casada (grupo de referencia) } \\
\hline Unida & 0.354 & 0.305 & 0.215 & 0.151 \\
\hline Separada & 0.101 & 0.111 & 0.195 & 0.194 \\
\hline Viuda & 0.068 & 0.081 & 0.171 & 0.198 \\
\hline Soltera & 0.133 & 0.174 & 0.217 & 0.282 \\
\hline \multicolumn{5}{|l|}{ Situación laboral de la PR (dummies) } \\
\hline \multicolumn{5}{|c|}{ Asalariada formal (grupo de referencia) } \\
\hline Asalariada no formal & 0.191 & 0.199 & 0.149 & 0.149 \\
\hline Cuenta propia $(\mathrm{CP})$ no profesional & 0.181 & 0.179 & 0.088 & 0.085 \\
\hline Cuenta propia (CP) profesional & 0.026 & 0.045 & 0.024 & 0.023 \\
\hline
\end{tabular}

“Visión de Futuro" Año 18, Volumen N²5 N², Edición Especial-III Congreso Regional de Economía del Norte Grande-Pág 1-30 URL de la Revista: http://visiondefuturo.fce.unam.edu.ar/index.php/visiondefuturo/index

URL del Documento: https://visiondefuturo.fce.unam.edu.ar/index.php/visiondefuturo/issue/view/20

ISSN 1668 - 8708 - Versión en Línea

E-mail: revistacientifica@fce.unam.edu.ar 


$\begin{array}{lllll}\text { Desocupada } & 0.108 & 0.076 & 0.055 & 0.033 \\ \text { Inactiva } & 0.285 & 0.338 & 0.445 & 0.515\end{array}$

Región de residencia del hogar (dummies)

Gran Buenos Aires (grupo de referencia)

$\begin{array}{lcccc}\text { Noroeste Argentino (NOA) } & 0.108 & & 0.104 & \\ \text { Nordeste Argentino (NEA) } & 0.060 & 0.051 & \\ \text { Cuyo } & 0.062 & 0.056 & \\ \text { Centro } & 0.214 & 0.215 & \\ \text { Patagonia } & 0.030 & & 0.037 & \\ \text { Muestra expandida } & 10,027,978 & 1,686,288 & 11,133,154 & 1,728,429\end{array}$

Fuente: Elaboración propia con datos de INDE-EPH. 
Tabla A.2. Determinantes de la sobre-pobreza en HJF

\begin{tabular}{|c|c|c|c|c|}
\hline \multirow{2}{*}{ Variable/Categoría } & \multicolumn{2}{|c|}{ Sólo pobres } & \multicolumn{2}{|c|}{ Sólo HJF } \\
\hline & Todas & Norte Grande & Todas & Norte Grande \\
\hline & [1] & [2] & [3] & [4] \\
\hline \multirow[t]{2}{*}{ Edad } & $1.075^{\star \star *}$ & $1.176^{\star \star \star}$ & 1.014 & 1.007 \\
\hline & $(0.015)$ & $(0.018)$ & $(0.010)$ & $(0.011)$ \\
\hline \multirow[t]{2}{*}{ Cuadrado de la edad } & $0.999^{* * *}$ & $0.998^{* * *}$ & $1.000^{* * *}$ & $1.000^{* * *}$ \\
\hline & $(0.000)$ & $(0.000)$ & $(0.000)$ & $(0.000)$ \\
\hline \multirow[t]{2}{*}{ Educación: 7-11 } & 0.937 & 1.068 & $0.503^{* * *}$ & $0.615^{* * *}$ \\
\hline & $(0.087)$ & $(0.096)$ & $(0.064)$ & $(0.054)$ \\
\hline \multirow[t]{2}{*}{ Educación: 12 y más } & $1.289^{\star *}$ & $1.268^{\star *}$ & $0.215^{\star \star \star}$ & $0.281^{* * *}$ \\
\hline & $(0.128)$ & $(0.122)$ & $(0.028)$ & $(0.026)$ \\
\hline \multirow[t]{2}{*}{ Niñas/os 0-4 } & 0.990 & $1.323^{* * *}$ & $1.273^{\star * \star}$ & $1.462^{* * *}$ \\
\hline & $(0.032)$ & $(0.041)$ & $(0.049)$ & $(0.047)$ \\
\hline \multirow[t]{2}{*}{ Niñas/os 5-12 } & 0.999 & $1.107^{* * *}$ & $1.738^{* * *}$ & $1.799^{* * *}$ \\
\hline & $(0.027)$ & $(0.025)$ & $(0.063)$ & $(0.048)$ \\
\hline \multirow[t]{2}{*}{ Niñas/os 13-17 } & $1.344^{* \star *}$ & $1.277^{* \star *}$ & $2.066^{\star * *}$ & $2.449^{\star * *}$ \\
\hline & $(0.046)$ & $(0.038)$ & $(0.088)$ & $(0.087)$ \\
\hline \multirow[t]{2}{*}{ Mayores 65-69 } & $0.693^{* * *}$ & $1.799^{* * *}$ & $0.711^{\star * *}$ & $0.689^{* * *}$ \\
\hline & $(0.074)$ & $(0.219)$ & $(0.057)$ & $(0.057)$ \\
\hline \multirow[t]{2}{*}{ Mayores 70-79 } & 0.828 & $1.355^{\star *}$ & $0.497^{* * *}$ & $0.496^{* * *}$ \\
\hline & $(0.103)$ & $(0.161)$ & $(0.045)$ & $(0.042)$ \\
\hline \multirow[t]{2}{*}{ Mayores 80 y más } & $0.749^{\star *}$ & $4.920^{\star * *}$ & $0.440^{\star * *}$ & $0.567^{\star * *}$ \\
\hline & $(0.105)$ & $(1.224)$ & $(0.051)$ & $(0.074)$ \\
\hline \multirow[t]{2}{*}{ Hogar unipersonal } & $0.174^{\star \star \star}$ & $0.106^{\star \star *}$ & $0.250^{\star * *}$ & $0.156^{\star * *}$ \\
\hline & $(0.039)$ & $(0.031)$ & $(0.037)$ & $(0.028)$ \\
\hline \multirow[t]{2}{*}{ Hogar nuclear sin hijas/os } & 1.111 & $2.217^{* * *}$ & $0.398^{* * *}$ & 0.859 \\
\hline & $(0.214)$ & $(0.498)$ & $(0.058)$ & $(0.139)$ \\
\hline \multirow[t]{2}{*}{ Hogar monoparental } & $3.919^{* * *}$ & $2.900^{* * *}$ & $1.813^{* * *}$ & $0.756^{* * *}$ \\
\hline & $(0.514)$ & $(0.329)$ & $(0.178)$ & $(0.068)$ \\
\hline \multirow[t]{2}{*}{ Hogar extenso } & $1.687^{* \star *}$ & $1.411^{* * *}$ & $1.478^{* * *}$ & 0.944 \\
\hline & $(0.117)$ & $(0.091)$ & $(0.135)$ & $(0.073)$ \\
\hline \multirow[t]{2}{*}{ Unida/o } & $1.314^{* * *}$ & 1.003 & $0.842^{* *}$ & $0.791^{* * *}$ \\
\hline & $(0.081)$ & $(0.060)$ & $(0.068)$ & $(0.066)$ \\
\hline \multirow[t]{2}{*}{ Separada/o } & $14.773^{\star * \star}$ & $12.759^{\star \star *}$ & $0.744^{\star * *}$ & $1.300^{* * *}$ \\
\hline & $(1.466)$ & $(1.285)$ & $(0.082)$ & $(0.112)$ \\
\hline \multirow[t]{2}{*}{ Viuda/o } & $11.151^{\star * \star}$ & $17.609^{\star \star *}$ & 0.863 & 0.859 \\
\hline & $(1.705)$ & (2.439) & $(0.095)$ & $(0.080)$ \\
\hline Soltera/o & $12.497^{\star \star *}$ & $17.542^{\star \star *}$ & 1.156 & $1.758^{\star * *}$ \\
\hline
\end{tabular}

"Visión de Futuro" Año 18, Volumen No 25 № 2, Edición Especial-III Congreso Regional de Economía del Norte Grande-Pág 1-30 URL de la Revista: http://visiondefuturo.fce.unam.edu.ar/index.php/visiondefuturo/index

URL del Documento: https://visiondefuturo.fce.unam.edu.ar/index.php/visiondefuturo/issue/view/20

ISSN 1668 - 8708 - Versión en Línea

E-mail: $\underline{\text { revistacientifica@fce.unam.edu.ar }}$ 


\begin{tabular}{|c|c|c|c|c|}
\hline & $(1.276)$ & $(1.644)$ & $(0.117)$ & $(0.147)$ \\
\hline \multirow[t]{2}{*}{ Asalariada/o no formal } & $2.441^{\star \star \star}$ & $2.058^{* \star *}$ & $5.450^{\star \star \star}$ & $5.482^{\star * *}$ \\
\hline & $(0.197)$ & $(0.173)$ & $(0.414)$ & $(0.454)$ \\
\hline \multirow[t]{2}{*}{ Cuanta propia no prof. } & 0.943 & 0.973 & $4.485^{\star * \star}$ & $5.208^{\star * *}$ \\
\hline & $(0.075)$ & $(0.085)$ & $(0.426)$ & $(0.475)$ \\
\hline \multirow[t]{2}{*}{ Cuenta propia prof.. } & $0.371^{* * *}$ & $0.463^{\star \star \star}$ & 1.000 & $1.862^{\star \star *}$ \\
\hline & $(0.064)$ & $(0.074)$ & $(0.158)$ & $(0.318)$ \\
\hline \multirow[t]{2}{*}{ Desempleada/o } & $1.401^{\star \star \star}$ & $1.305^{\star \star}$ & $6.887^{\star \star \star}$ & $9.674^{\star * *}$ \\
\hline & $(0.138)$ & $(0.142)$ & $(0.757)$ & $(1.418)$ \\
\hline \multirow[t]{2}{*}{ Inactiva/o } & $17.342^{* * *}$ & $12.189^{* * *}$ & $6.995^{\star * *}$ & $5.307^{* * *}$ \\
\hline & $(1.411)$ & $(1.038)$ & $(0.530)$ & $(0.381)$ \\
\hline \multirow[t]{2}{*}{ NOA } & $0.769^{* \star *}$ & & 0.965 & \\
\hline & $(0.044)$ & & $(0.052)$ & \\
\hline \multirow[t]{2}{*}{ NEA } & $0.625^{\star \star *}$ & & $1.188^{\star * *}$ & \\
\hline & $(0.039)$ & & $(0.072)$ & \\
\hline \multirow[t]{2}{*}{ Cuyo } & $0.495^{\star \star *}$ & & $0.873^{\star *}$ & \\
\hline & $(0.037)$ & & $(0.057)$ & \\
\hline \multirow[t]{2}{*}{ Centro } & $0.744^{\star \star *}$ & & 1.065 & \\
\hline & $(0.042)$ & & $(0.055)$ & \\
\hline \multirow[t]{2}{*}{ Patagonia } & $0.846^{* *}$ & & $0.857^{* *}$ & \\
\hline & $(0.059)$ & & $(0.052)$ & \\
\hline \multirow[t]{2}{*}{ Ordenada } & $0.035^{* * *}$ & $0.004^{* * *}$ & $0.350^{* * *}$ & $0.362^{* * *}$ \\
\hline & $(0.012)$ & $(0.002)$ & $(0.097)$ & $(0.106)$ \\
\hline Pseudo-R ${ }^{2}$ & 0.375 & 0.378 & 0.316 & 0.299 \\
\hline Observaciones & 37,458 & 14,031 & 40,169 & 14,766 \\
\hline
\end{tabular}

Nota: Significativamente diferente de cero al ${ }^{*} 10 \%,{ }^{* *} 5 \%,{ }^{* * *} 1 \%$. Entre paréntesis se reportan los desvíos estándar (valores absolutos).

Fuente: Elaboración propia con datos de INDE-EPH.

\section{REFERENCIAS}

Aguilar, P. (2011) "La feminización de la pobreza: conceptualizaciones actuales y potencialidades analíticas" R. Katál., 14(1): 126-133.

Aisa, R.; Larramona, G. \& Pueyo, F. (2019) "Poverty in Europe by Gender: The role of education and labour status" Economic Analysis and Policy 63: 24-34.

AlAzzawi (2015) Is there Feminization of Poverty in Egypt? Working Paper Series, Economic Research Forum, Dokki, Giza.

Arévalo, C., y Paz, J. (2015). Pobreza en la Argentina. Privaciones múltiples y asimetrías regionales. IELDE, Documento de trabajo Nro. 15, primavera, Salta. 
Ariza, M. y de Oliveira, O. (2001). "Familias en transición y marcos conceptuales en redefinición" Papeles de Población, Nro. 28: 9-39.

Binstock, G. (2018) “Hogares y organización familiar" En Piovani, J. \& Salvia, A. (Compiladores) La Argentina en el siglo XXI. Cómo somos, vivimos y convivimos en una sociedad desigual. Siglo XXI Editores, Buenos Aires: 421-442.

Blinder, A. (1973). "Wage Discrimination: Reduced Form and Structural Estimates" The Journal of Human Resources, 8(4): 436-455.

Bradshaw, S. Sylvia Chant \& Brian Linneker (2019) Challenges and Changes in Gendered Poverty: The Feminization, De-Feminization, and Re-Feminization of Poverty in Latin America, Feminist Economics, 25:1, 119-144, DOI: 10.1080/13545701.2018.1529417.

Buvinic, M., \& Gupta, G. R. (1997) "Female-Headed Households and Female-Maintained Families: Are They Worth Targeting to Reduce Poverty in Developing Countries?" Economic Development and Cultural Change, 45 (2), 259-280.

Cortés, F. (1997), "Determinantes de la pobreza de los hogares. México, 1992", Revista Mexicana de Sociología, México, volumen $59, \mathrm{~N}^{\circ} 2$.

Fairlie, R. (2005). "An extension of the Blinder-Oaxaca decomposition technique to logit and probit models" Journal of Economic and Social Measurement, 30: 305-316.

González Rosada, M. (2019) Feminización de la pobreza en Argentina, Foco Económico, marzo, disponible en: https://focoeconomico.org/2019/03/20/feminizacion-de-lapobreza-en-argentina/.

González, F. (2019) Pobreza multidimensional urbana en Argentina: Un análisis de las disparidades entre el Norte Grande y Centro-Cuyo-Sur (2003-2016), tesis de maestría Universidad Nacional del Sur, Bahía Blanca.

Instituto Nacional de Estadística y Censos (INDEC, 2016) La medición de la pobreza y la indigencia en la Argentina, Metodología INDEC № 22, Buenos Aires.

Instituto Nacional de Estadística y Censos (INDEC, 2020a) Mercado de trabajo. Tasas e indicadores socioeconómicos (EPH), Trabajo e ingresos, vol. 4, $n^{\circ} 3$, primer trimestre de 2020, Buenos Aires.

Instituto Nacional de Estadística y Censos (INDEC, 2020b) Evolución de la distribución del ingreso (EPH), Trabajo e ingresos, vol. 4, $\mathrm{n}^{\circ} 4$, segundo trimestre de 2020, Buenos Aires.

Jann, B. (2008). "The Blinder-Oaxaca decomposition for linear Models" The Stata Journal, 8(4): 453-479.

Kynch, J. \& Sen, A. (1983) "Indian women: well-being and survival" Cambridge Journal of Economics, 7: 363-380.

\footnotetext{
"Visión de Futuro" Año 18, Volumen No 25 Nº 2, Edición Especial-III Congreso Regional de Economía del Norte Grande-Pág 1-30 URL de la Revista: http://visiondefuturo.fce.unam.edu.ar/index.php/visiondefuturo/index

URL del Documento: https://visiondefuturo.fce.unam.edu.ar/index.php/visiondefuturo/issue/view/20 
Liu, Ch.; Esteve, A. \& Treviño, R. (2017) "Female-Headed Households and Living Conditions in Latin America" World Development, 90(C): 311-328.

Mazzeo, V. (2008) Las familias monoparentales en Argentina: la importancia de la jefatura femenina. Diferencias regionales, 1980-2001, ponencia presentada al congreso de ALAP, Córdoba.

Medeiros, M. \& Costa, J. (2008) "Is There a Feminization of Poverty in Latin America?" World Development 36(1): 115-27.

Ministerio de Trabajo, Empleo y Seguridad Social (MTESS, 2019) Informe sobre la situación de género en el sistema de riesgos del trabajo, Superintendencia de Riesgos del Trabajo, Departamento de Estudios Estadísticos Gerencia Técnica, Buenos Aires.

Oaxaca, R. (1973). "Male-female wage differentials in urban labor markets" International Economic Review, 14(3): 693-709.

Oaxaca, R. and Ransom, M. (1988). "Searching for the Effect of Unionism on the Wages of Union and Non-Union Workers” Journal of Labor Research 9: 139-148.

Paz, J. (2019a) "La brecha salarial por género en Argentina: análisis acerca de la segmentación laboral" Soc. e Cultura., Goiânia, 22(1): 157-178.

Paz, J. (2019b) La pobreza en la Argentina. Explorando más allá de los ingresos y más allá de los promedios (Incidencia, composición y evolución 2004-2019). IELDE, Documento de Trabajo Nro.21.

Paz, J. (2020) Introducción al estudio de la segregación ocupacional por género en la Argentina. Documentos de Trabajo RedNIE, 2020-10.

Pearce, D. (1978) "The feminization of poverty: women, work and welfare" Urban and Social Change Review, 11, 28-36.

Rajkarnikar, J. \& Ramnarain, S. (2019) "Female Headship and Women's Work in Nepal" Feminist $\quad$ Economics, DOI: 10.1080/13545701.2019.1689282, https://doi.org/10.1080/13545701.2019.1689282.

Ravallion, M. (2016). The Economics of Poverty. History, Measurement and Policy. Oxford University Press, London.

Snyder, A.; McLaughlin, D. \& Findeis, J. (2006) "Household Composition and Poverty among Female-Headed Households with Children: Differences by Race and Residence" Rural Sociology 71(4): 597-624.

\footnotetext{
"Visión de Futuro" Año 18, Volumen No 25 N 2, Edición Especial-III Congreso Regional de Economía del Norte Grande-Pág 1-30 URL de la Revista: http://visiondefuturo.fce.unam.edu.ar/index.php/visiondefuturo/index

URL del Documento: https://visiondefuturo.fce.unam.edu.ar/index.php/visiondefuturo/issue/view/20 


\section{RESUMEN BIBLIOGRÁFICO}

\section{Jorge Augusto Paz}

Doctor en Economía (UCEMA, 2007) y doctor en Demografía (UNC, 2018). Investigador principal del Consejo Nacional de Investigaciones Científicas y Técnicas (CONICET), Investigador categoría 1 del programa de incentivos (Ministerio de Educación de la Nación) y profesor regular titular de la Universidad Nacional de Salta. Dirige el Instituto de Estudios Laborales y del Desarrollo Económico (IELDE) y la Maestría en Economía del Desarrollo (MED), Universidad Nacional de Salta.

Miembro del Consejo Asesor para el proyecto de Pobreza Crónica (CIPPEC) e investigador asociado del Centro de Estudios sobre Desarrollo Humano (CEDH) Universidad de San Andrés. Investigador del Proyecto Internacional National Transfer Accounts (NTA) del Center for the Economics and Demography of Aging, University of California at Berkeley.

Ha sido investigador asociado en la División de Población de la Comisión Económica para América Latina y el Caribe (CEPAL). Ha liderado y lidera proyectos del Fondo de Naciones Unidas para la Infancia (UNICEF Argentina y Brasil), del Fondo de Naciones Unidas para Actividades de Población (UNFPA), el Banco Mundial (BM), Banco Interamericano de Desarrollo (BID), el Centro Latinoamericano y Caribeño de Demografía (CELADE-CEPAL), la Oficina Internacional del Trabajo (OIT). Colabora y colaboró con el Fondo de Capital Social (FONCAP) y la Organización de Estados Iberoamericanos (OEI), y con los gobiernos provinciales (Buenos Aires, Mendoza, Tucumán y Salta), y nacional de la República Argentina.

Ha publicado 9 libros y más de 30 artículos en revistas académicas.

\section{Carla Arevalo}

Doctora en Demografía por la Universidad Nacional de Córdoba. Magíster en Economía por la Universidad Nacional de La Plata. Becaria Posdoctoral del CONICET con lugar de trabajo en el Instituto de Estudios Laborales y del Desarrollo Económico (IELDE). Economista, docente de Desarrollo Económico en la Universidad Nacional de Salta. 